\section{Bullying in schools}

\section{Author's reply}

EDrroR,-I agree with Vidya Rao that schools should be encouraged to tackle bullying.' In my clinical experience, however, parents have not necessarily already taken the matter up with the school. Many parents have not even known that their child was being bullied, and those who have approached the school have often had the response, "We don't have bullying in this school."

Schools can do much to reduce bullying. In Norway a national campaign was mounted after three children committed suicide as a result of bullying. A number of measures at the school, class, and individual levels were used. The frequency of bully-victim problems decreased by half during the following two years. ${ }^{2}$ Rates of truancy and antisocial behaviours in general also dropped, and pupils' satisfaction with school life improved. In Britain the Department of Education's Sheffield bullying project evaluated a similar intervention programme. The results of this were published last year, ${ }^{3}$ together with clear practical advice for teachers. ${ }^{4}$ This research provided the basis for the Department for Education's guidelines.'

In my editorial I hoped to raise doctors' awareness of bullying, its effects on the child, and what can be done in the hope that together doctors, parents, and schools can prevent the continued abuse of victims of bullying in schools. ${ }^{6}$

JUDITH DAWKINS

Department of Mental Health Sciences,

St George's Hospital Medical School,

London SW17 ORE

1 Rao V. Bullying in schools. BMf 1995;310:1065-6. (22 April.)

2 Olweus D. Bully/victim problems among schoolchildren: basic facts and effects of a school based intervention program. In: Pepler D, Rubin K, eds. The development and treatment of childhood aggression. Hillsdale, NJ: Erlbaum, 1991.

3 Smith PK, Sharp S. School bullying: insights and perspectives. London: Routledge, 1994.

4 Sharp S, Smith PK. Tackling bullying in your school: a practical handbook for teachers. London: Routledge, 1994.

5 Department for Education. Bullying: don't suffer in silence-an anti-bullying pack for schools. London: HMSO, 1994.

6 Dawkins J. Bullying in schools: doctors' responsibilities. BMF 1995;310:274-5. (4 February.)

\section{Smoking and death}

EDIToR,-The Nazi ideology and movement were more effective with regard to eugenics than with regard to external threats to health.' Statistics on cigarette production between 1932 and 1944 show an upward trend and an increase of $100 \%$ (figure $)^{2}$ : The peak was reached in 1940 and can be compared with the 130 billion cigarettes consumed in Germany today. ${ }^{3}$ The firm Reemtsma controlled $80 \%$ of the market at that time, and the early attacks of the SA (Sturmabteilung) movement

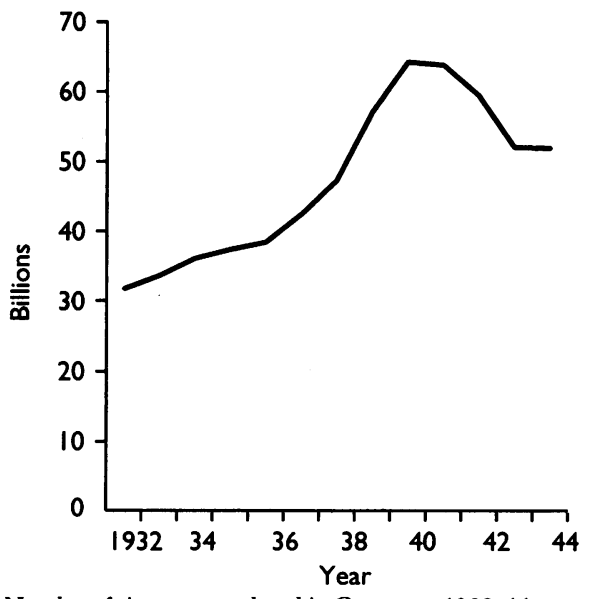

Number of cigarettes produced in Germany, 1932-44 against the firm were counteracted by a DM10m donation via Goering to the Adolf Hitler fund. ${ }^{2}$

The popularity of the antismoking coalition within the Nazi movement $t^{4}$ came to an end with the beginning of the second world war. The overriding interests of the morale and fighting capacity of the army meant that free cigarettes for soldiers were a necessity. Like the first world war had been, the second world war was the impetus for a new generation of men and women in Germany, Britain, and the United States to take up smoking. For the Nazis, smoking and drinking were only two of the sources of a degenerative "Volksgesundheit." The Nazis were surely flexible enough not to let their aim of conquering the world be spoiled by antismoking campaigns. In saying that Hitler caused the second world war one has also to say that by this he caused a large part of the smoking epidemic of the ' 50 s in the world. The universal concept of causation counts deaths irrespective of their origin. Smoking does not kill; i poses a risk to your health. Peto overstates his message by comparing 50 million deaths from smoking and Nazism. ${ }^{6}$

DIETER BORGERS Head, department of epidemiolog Landesinstitut für den Offentlichen Gesundheitsdienst, D-33611 Bielefeld,

Germany

1 Peto R. Smoking and death: the past 40 years and the next 40 BMF 1994;309:937-9.

2 Pritzkoleit K. Auf einer Woge von Gold. Munich, Zürich Droemer und Knauer, 1964.

3 Borgers D, Hueck C. Tabakmultis und Gesundheitspolitik. In fahrbuch fur kritische Medizin 8. Berlin: Argument, 1982.

4 Smith DA, Ströbele SA, Egger M. Smoking and health promotio in Nazi Germany. $\mathcal{F}$ Epidemiol Community Health 1994;48: 220-3.

5 Smith GD, Ströbele S, Egger M. Smoking and death. $B M F$ 1995;310:396.

6 Peto R. Smoking and death. BMF 1995;310:396.

\section{Babies' deaths linked to suboptimal care}

EDITOR,-When a government report states that over $40 \%$ of deaths during birth are linked to substandard care both those managing labour and those purchasing maternity care wish to know how practice can be changed to reduce the number of such deaths.' Changes to practice should be based on firm, scientifically based evidence.

The confidential inquiry into stillbirths and deaths in infancy has not set standards for care, "substandard" being decided at a regional level on the basis of individual cases. In contrast, the inquiry into maternal deaths has produced guidelines for good practice. ${ }^{23}$ Therefore, how valid are these estimates of substandard care, and how does one interpet differences among regions as the inquiry has not published interobserver studies? Until criteria for substandard care are set and interregional variation has been assessed it is misleading to publish these data without expressing considerble caution.

The inquiry examines only deaths, and the denominator of intrapartum care that does not result in death is ignored. There can therefore be only a speculative association between substandard care, however defined, and outcome. Before investigating certain factors further one would wish to establish that the level of substandard care in normal labours is different. Case-control studies may overcome such problems, but with the increasing use of obstetric computer databases in maternity care it should be possible to assess the risk associated with substandard care by multivariate analysis, using data from all intrapartum events.

Confidential inquiries may be useful audit tools, although there is no firm evidence of their effectiveness. Inquiries such as the confidential inquiry into stillbirths and deaths in infancy will not improve our knowledge of the antecedents to death unless rigorous epidemiological and clinical research methodologies are used to answer specific objectives.

CHARLES D A WOLFE Clinical director of obstetrics nd gynaecolog

Guy's and St Thomas's Hospitals Trust,

London SE1 7EH

1 Dillner L. Babies' deaths linked to suboptimal care. $B M \mathcal{F}$ 1995;310:757. (25 March.)

2 Confidential inquiry into stillbirths and deaths in infancy. Part one. London: HMSO, 1995.

3 Report on confidential inquiries into maternal deaths in the United Kingdom 1988-1990. London: HMSO, 1994.

\section{Errors in administration of intravenous drugs}

EDITOR,-An audit to identify the type, rate, and potential severity of errors associated with medical and nursing staff administering intravenous drugs was carried out at the Royal Belfast Hospital for Sick Children over a four week period.

The disguised observation technique was used, whereby the observer accompanied the person involved in preparing and giving each dose. ${ }^{1}$ The errors were classified as incorrect administration rate and time $>30$ minutes from the prescribed time) and as incorrect diluent or volume, incorrect administration method (bolus or infusion), dose duplication, and omission. One hundred and seventy nine intravenous doses were observed, 132 given by senior house officers and 47 by nurses.

A total of 291 errors were detected in 168 of the observed doses, of which 237 were by senior house

Number (percentage) of errors in giving intravenous drugs

\begin{tabular}{lccc}
\hline & $\begin{array}{c}\text { Doses given } \\
\text { by senior } \\
\text { house officers } \\
(\mathrm{n}=132)\end{array}$ & $\begin{array}{c}\text { Doses given } \\
\text { by nurses } \\
(\mathrm{n}=47)\end{array}$ & $\begin{array}{c}\text { Total } \\
(\mathrm{n}=179)\end{array}$ \\
Error type & $105(80)$ & $35(74)$ & $140(78)$ \\
Incorrect time & $104(79)^{\star}$ & $10(21)$ & $114(63)$ \\
Incorrect rate & $16(12)$ & $8(17)$ & $24(13)$ \\
Incorrect volume & $1(1)$ & 0 & $1(1)$ \\
Incorrect diluent & $8(6)$ & $1(2)$ & $9(5)$ \\
Incorrect method & $1(1)$ & 0 & $1(1)$ \\
Dose duplication & $2(1)$ & 0 & $2(1)$ \\
Dose omission & 237 & 54 & 291 \\
\hline Total errors & & &
\end{tabular}

$\star \mathrm{P}<0.001$.

officers (table). Of the 132 doses given by senior house officers, $129(98 \%)$ had at least one error, compared with 39 of the 47 doses $(83 \%)$ given by nurses. Forty eight per cent of errors were associated with an incorrect administration time, with only $20 \%$ of the doses given at the correct time by the senior house officers and $26 \%$ by nurses. Nurses gave $79 \%$ of their doses at the recommended rate; only $21 \%$ of the doses given by senior house officers were correct. Fifty five per cent of doses were given in less than 30 seconds (all by senior house officers). Most diluent volume errors occurred when nurses used the intramuscular rather than the intravenous reconstitution volume. Two doses were omitted, one dose was duplicated, and on one occasion the wrong diluent was used for a drug.

Yates corrected $\chi^{2}$ test showed a highly significant $(P=0.0011)$ increased overall error rate when senior house officers administered the intravenous drugs, the major error being an inappropriately fast rate of administration. No potentially lethal or serious errors were observed, and the rate of clinically significant errors as defined by Folli $e t a l^{2}$ was $3.3 \% ; 83 \%$ of these were attributed to senior house officers.

This study shows that errors in intravenous administration of drugs are statistically more likely 
with busy junior medical staff than with nurses, who have formal training and operate a double checking system. Administration of intravenous drugs by nurses not only reduces the workload of senior house officers but should also improve the quality of care.

MC B O'HARE Research pharmacis A M BRADLEY

Royal Hospitals, Pharmacist

Belfast BT12 6BE

T GALLAGHER Consultant anaesthetis

M D SHIELDS Consultant paediatrician

Royal Belfast Hospital for Sick Children

Belfast

1 Barker KN, McConnell WE. The problems of detecting medication errors in hospitals. Am $\mathcal{J}$ Hosp Pharm 1962;19. $360-9$.

2 Hugo L, Robert I, Benitz WE, Russo JC. Medication erro prevention by clinical pharmacists in two children's hosptals. Pediatrics 1987;79:718-22.

\section{Protection of the individual in biomedical research in Africa}

EDITOR,-Progress in biomedical science is often due to more and more complex experimentation on humans. The limits of this research need to be defined in terms of science and ethics. Biomedica research in African countries, as in many developing countries, is often carried out without a lega basis: in many African countries there is no legislation on scientific research. Western countrie have done, or are doing, their best to adopt legislation about scientific research practice that respects the individual ${ }^{1-3}$; can Africa stay away from these fundamental changes?

Each African country should have a national ethics committee, and at the top there should be a federal bureau of inter-African ethics and of protection of the individual along the lines of the Organisation for African Unity; this federal bureau should work in close collaboration with the regional bureau of the World Health Organisation. The advantages for the African countries would be considerable: common aims, exchanges of materials and research workers, interchanges of ideas, and stimulation of research in general. Foreign partners wanting to make biomedical assays in, or to conduct experiments on, humans in Africa would have to seek authorisation from the inter-African bureau before submitting these projects to national African ethics committees. These African countries would be the copromoters of the biomedical research carried out there. For big projects the WHO, with the agreement of the inter-African bureau, should stand as copromoter and assume its obligations in these often impoverished African countries. Foreign investigators should obtain in their home countries the authorisation necessary to carry out such biomedical research in foreign countries.

Although many patients in some African countries may not have the educational background needed to be really informed, informed consen remains necessary. Investigators should adapt to cultural and educational realities in these countries. For biomedical research to be better organised in African countries we need to foster openness and improve ethical standards to better protect the individual.

\section{MAURICE MANOUANA}

Department of Obstetrics and Gynaecology,

Centre Hospitalier Saint-Cyr,

Service de Gynecologie-Obstetrique

BP 319 ,

F-47300 Villeneuve-sur-Lot,

France

1 Moodie PCE, Marshall T. Guidelines for local research ethics committees. BMF 1992;304:1293-5.
2 Neuberger J. Ethics and health care: the role of research ethics committees in the United Kingdom. London: King's Fund Institute, 1992.

3 Pompidou A. A European approach for biomedical ethics. Eur $\mathcal{f}$ Med 1992;1:49-51.

\section{Effect of albumin on diuretic treatment in the nephrotic syndrome}

EDITOR,-Fehmi Akcicek and colleagues have addressed the question whether albumin has an additive effect on the diuretic treatment of patients with the nephrotic syndrome. ${ }^{1}$ We have published similar results, but besides plasma volume expansion we also studied the effect of different plasma and urinary albumin concentrations. ${ }^{2}$ The same plasma volume expansion of about $20 \%$ was achieved by infusing either $40 \mathrm{~g}$ of albumin or $36 \mathrm{~g}$ of dextran 70 (Macrodex, Pharmacia AB, Sweden) in five nephrotic patients on separate study days. The plasma albumin concentration increased from $28 \mathrm{~g} / 1$ to $33 \mathrm{~g} / 1$ after albumin and decreased to $23 \mathrm{~g} / 1$ after dextran. Urinary albumin excretion was unchanged after dextran but increased by $70 \%$ from 3.9 to $6.6 \mathrm{~g} / 24 \mathrm{~h}$ after albumin. Dextran caused a considerable increase and albumin a small increase in renal blood flow (para-aminohippuric acid clearance). The glomerular filtration rate (inulin clearance) did not change after albumin or dextran infusions.

Both modes of volume expansion caused a moderate increase in the rate of urinary flow but not in the rate of excretion of sodium. The renal sensitivity to frusemide was the same after dextran and albumin. Thus, even within the pathophysiological range of urinary albumin excretion, frusemide binding to urinary albumin does not seem to impair its diuretic effect.

After 24 hours the plasma volume and plasma albumin concentration had almost returned to initial values with all protocols. Moreover, rebound effects of frusemide were seen four to 20 hours after the dose, irrespective of plasma volume expansion. Thus the additive ( 24 hour) diuretic and natriuretic effects of plasma volume expansion and increased plasma albumin concentration to an intravenous injection of $40 \mathrm{mg}$ of frusemide in nephrotic patients were small and short lasting and thus of negligible clinical importance.

\section{PER A SJÖSTRÖM}

Department of Internal Medicine, Head of dialysis unit

Orebro Medical Centre Hospital,

S-701 85 Orebro,

Sweden

BO G ODLIND

Department of Medical Pharmacology,

University of Uppsala

Uppsala,

1 Akcicek F, Yalniz T, Basci A, Ok E, Dorhout Mees EJ. Diuretic effect of frusemide in patients with nephrotic syndrome: is it potentiated by intravenous albumin? BMF 1995;310:162-3. (21 January.)

2 Sjöström PA, Odlind BG, Beermann BA, Karlberg BE. Pharmacokinetics and effects of frusemide in patients with the nephrotic syndrome. Eur f Clin Pharmacol 1988;37:173-80.

\section{Suppression of medical conditions by Cushing's syndrome}

EdrTor,-Alan Steuer and colleagues describe the unusual occurrence of a medical condition (sarcoidosis) that was suppressible by steroids and presented shortly after surgical treatment of Cushing's syndrome. ${ }^{1}$ The corollary of thisnamely, that a pre-existing medical condition may be suppressed by the onset of Cushing's syndrome, reflecting the increased output of corticosteroidsis also true and may help diagnosis.

The case of a 66 year old man who presented with diarrhoea and had been found to have advanced medullary carcinoma of the thyroid gland 11 years earlier illustrates this point. At recent review he complained of polydipsia and polyuria. Several weeks before he had noted that his persistent psoriasis had entirely resolved. (It had been troublesome for over 50 years and had been only partially controlled by dithranol and betamethasone preparations. Since 1976 it had been associated with arthropathy, for which he required intermittent non-steroidal anti-inflammatory drugs.) Further questioning and examination elicited fatigue with proximal myopathy and a plethoric face but no excess pigmentation. Blood pressure was $120 / 70 \mathrm{~mm} \mathrm{Hg}$. Investigations confirmed diabetes mellitus associated with Cushıng's syndrome (potassium concentration $2.7 \mathrm{mmol} / 1$, bicarbonate $>40 \mathrm{mmol} / \mathrm{l}$, serum cortisol persistently $>1660 \mathrm{nmol} / \mathrm{l}$, urinary free cortisol $3120 \mathrm{nmol} / 24 \mathrm{~h}$, and adrenocorticotrophic hormone 267-316 ng/l (normal 7-51 ng/l)). Carcinoembryonic antigen and calcitonin concentrations were appreciably increased. His Cushing's syndrome responded to metyrapone. He became increasingly pigmented and continued chemotherapy with cisplatin and fluorouracil for his metastatic medullary carcinoma of the thyroid, which was the presumed source of his adrenocorticotrophic hormone.

The onset of this patient's Cushing's syndrome was clearly rapid; he had not developed some of the more typical signs of the condition, such as thin skin and easy bruising, and had not developed excess pigmentation. Despite his metabolic upset and symptoms he considered the clearing of his psoriasis to have been an early and prominen feature. We suggest that it may be worth actively seeking such information from patients with suspected Cushing's syndrome, particularly when the diagnosis does not seem clinically obvious, in the hope of identifying the condtion at an early stage. The suppression of pre-existing medical conditions may help to identify the time of onset of hypersecretion of glucocorticoid.

DAVID WALMSLEY Senior registra JOHN S BEVAN

Aberdeen Royal Infirmary JOHN S BEVAN Aberdeen AB9 2ZB

1 Steuer A, Cavan DA, Lowy C. Sarcoidosis presenting after resection of an adrenocortical adenoma. BMF 1995;310:567-8. (4 March.)

\section{Lord Moran's prescriptions for Churchill}

EDITOR,-In 1992 when my biography of Lord Moran was published, I divulged no information from medical records that had not already been publicly mentioned.' In describing Moran's management of Churchill's illnesses the constituents of pills that were prescribed-which various writers, including Churchill himself, referred to by nicknames such as "Morans" and "minors"remained unidentified.

Some of the drugs have become of interest to medical historians, especially in light of recent advances in knowledge of the treatment of the atherosclerotic disease that would have been the basis for Churchill's repeated cerebrovascular episodes. I therefore sought permission from the present Lord Moran, who owns his father's records, and from Sir Winston Churchill's surviving child, Lady Soames, to identify the various medications. Both have kindly consented.

From 1940 onwards, Moran prescribed "reds" to promote sleep. "Reds" were quinalbarbitone 